\title{
Management of Psoriatic Arthritis: Turkish League Against Rheumatism (TLAR) Expert Opinions
}

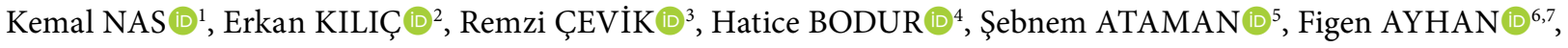 \\ Özgür AKGÜL(1) ${ }^{8}$, Ayşen AKINCI(1) 9 , Zuhal ALTAY (10 ${ }^{10}$, Erhan Çapkın (1) ${ }^{11}$, Abdullah Zübeyir DAĞLI(12,

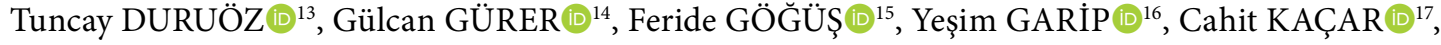 \\ Ayhan KAMANLI (18), Ece KAPTANOĞLU (1) ${ }^{19}$, Taciser KAYA (1020, Hilal KOCABAŞ (1021,

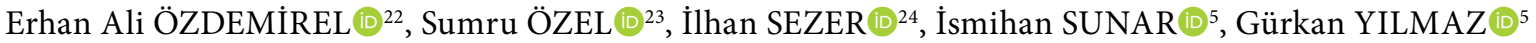

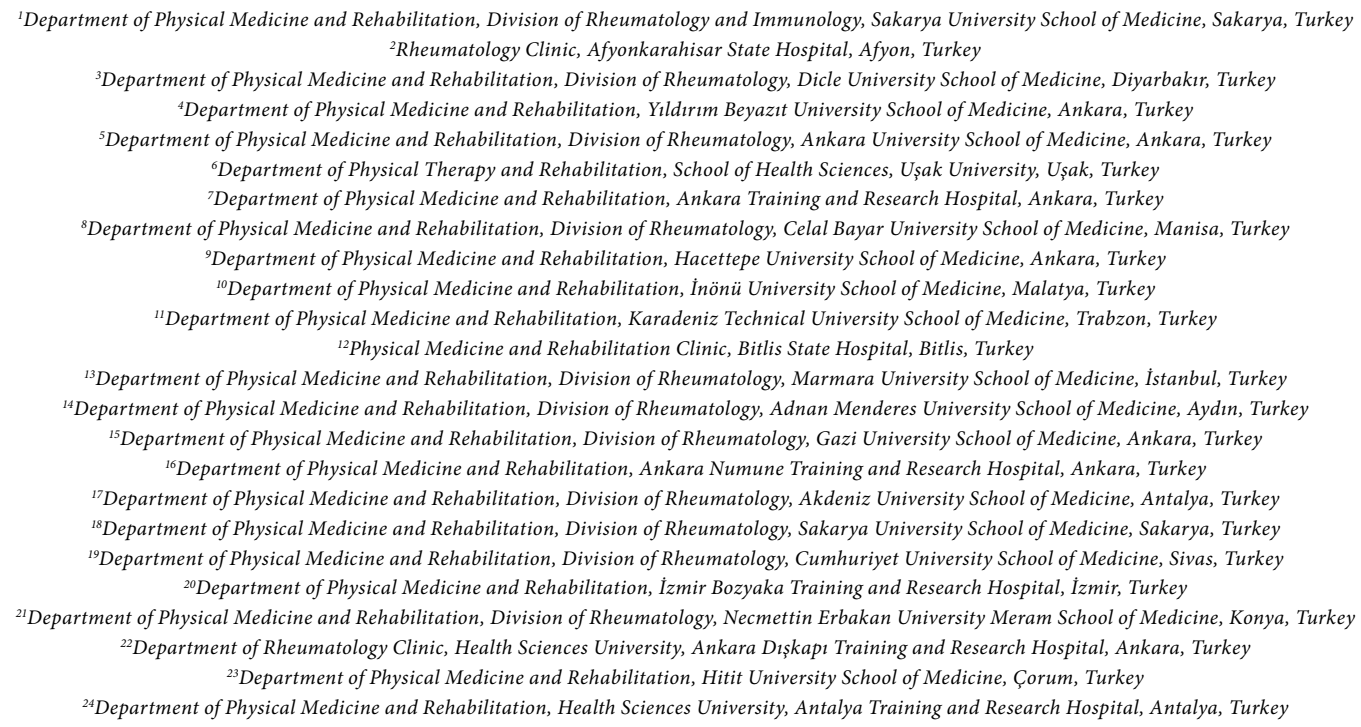

\section{ABSTRACT}

Objectives: This study aims to establish the first national treatment recommendations by the Turkish League Against Rheumatism (TLAR) for psoriatic arthritis (PsA) based on the current evidence.

Materials and methods: A systematic literature review was performed regarding the management of PsA. The TLAR expert committee consisted of 13 rheumatologists and 12 physical medicine and rehabilitation specialists experienced in the treatment and care of patients with PsA from 22 centers. The TLAR recommendations were built on those of European League Against Rheumatism (EULAR) 2015. Levels of evidence and agreement were determined.

Results: Recommendations included five overarching principles and 13 recommendations covering therapies for PsA, particularly focusing on musculoskeletal involvement. Level of agreement was greater than eight for each item.

Conclusion: This is the first paper that summarizes the recommendations of TLAR as regards the treatment of PsA. We believe that this paper provides Turkish physicians dealing with PsA patients a practical guide in their routine clinical practice.

Keywords: Expert opinions; management; psoriatic arthritis; treatment recommendation; Turkish League Against Rheumatism. 
Psoriatic arthritis (PsA) is a highly heterogeneous disease. Patients with PsA may have combinations of peripheral arthritis, axial disease, enthesitis, dactylitis, skin, and nail involvement. The severity of the disease varies widely between both disease domains and individual patients. As a result of understanding the pathophysiology of PsA, new strategies and targeted therapies have been developed for treatment in patients with PsA. ${ }^{1}$ Treatment of patients with PsA should include pharmacological and non-pharmacological methods, and be determined by patient and physician's shared decision. Recently, many disease-modifying antirheumatic drugs (DMARDs) have been made available for the treatment of PsA in Turkey, and others will be available within the next few years. DMARDs have been recently classified into three groups according to their pharmacological structure and mechanism of action: conventional synthetic (csDMARDs), biologic (bDMARDs) and targeted synthetic DMARDs (tsDMARDs). ${ }^{2}$ The most reliable, practical and best overlapping information for everyday use were issued through classification criteria and treatment recommendations by reputable organizations, or national recommendations of some countries. Clinicians may have difficulties in choosing an appropriate treatment approach due to the heterogeneity of PsA. To help this issue, along with some countries, international groups such as Group for Research and Assessment of Psoriasis and Psoriatic Arthritis (GRAPPA) and European League Against Rheumatism (EULAR) have published treatment recommendations for PsA. ${ }^{3-7}$ GRAPPA published its first PsA treatment recommendations in 2009, which were updated in 2015 due to the introduction of clinical use of new therapies. ${ }^{3,5}$ GRAPPA distinguishes the disease to six clinical types according to disease activity and severity of disease (peripheral arthritis, axial disease, enthesitis, dactylitis and skin and nail involvement) and describes the treatment according to these clinical types. The EULAR recommendations suggest an algorithmic approach that focuses on musculoskeletal lesions, particularly peripheral arthritis. Skin and nail lesions are considered separately, and if relevant psoriatic skin lesion is present, consultation is recommended with the dermatologist. Since 2012, due to the approval of new drugs and accumulation of data on use of new drugs, both GRAPPA and EULAR 2015 updated their recommendations for treatment of PsA. Therefore, in this study, we aimed to establish the first national treatment recommendations by the Turkish League Against Rheumatism (TLAR) for PsA based on the current evidence.

\section{MATERIALS AND METHODS}

The TLAR expert committee consists of 25 participants experienced in the treatment and care of patients with PsA from 22 centers. The expert committee was comprised of 13 rheumatologists and 12 physical medicine and rehabilitation specialists (two also had immunology $\mathrm{PhD}$ while the other two were rheumatology fellows-in-training). To establish TLAR treatment recommendations, the literature search was carried out between September 2017 and December 2017. The systematic literature search was performed on PubMed-MEDLINE and Scopus database with convenient key words and the included articles were published in English between 2015 and 2017. Randomized controlled trials (RCTs), systematic reviews, and meta-analyses including pharmacological and non-pharmacological treatments were searched attentively. The following search terms (synonyms and combinations) were used for pharmacological treatment: 'psoriatic arthritis' OR 'PsA' AND 'biologics' OR 'infliximab' OR 'etanercept' OR 'adalimumab' OR 'golimumab' OR 'certolizumab' OR 'tocilizumab' OR 'abatacept' OR 'tofacitinib' OR 'apremilast' OR 'ustekinumab' OR 'secukinumab' OR 'ixekizumab' OR 'TNF' OR 'jak' OR 'PDE' OR 'IL17' OR 'IL12/23'. The searched literature work was sent via e-mail to members of the expert committee prior to meeting. The first meeting was held in October 2017. The TLAR recommendations were built on those of EULAR 2015. At the first meeting, the items to be developed on the EULAR recommendations were discussed with 25 panelists. The second and third meetings were held electronically. At the second meeting in December 2017, draft items were discussed and opinions and contributions were received electronically. The final form of five overreaching principles and 13 recommendations were voted during the third meeting in January 2018. Assessment of level of agreement (LoA) was performed by using 0 to 10 scale, 0 meaning 
Table 1. Categorization of levels of evidence and grades of recommendation

\begin{tabular}{lll}
\hline \multicolumn{2}{l}{ Levels of evidence } & Grades of recommendation \\
\hline $1 \mathrm{a}$ & Systematic literature review of randomized controlled trials & \\
$1 \mathrm{~b}$ & At least one randomized controlled trial & A: Derived from level 1 evidence \\
$2 \mathrm{a}$ & At least one controlled study without randomization & B: Derived from level 2 evidence or extrapolated from level 1 evidence \\
$2 \mathrm{~b}$ & At least one quasi-experimental study & \\
3 & Descriptive studies (comparative, correlation, case-control) & C: Derived from level 3 evidence or extrapolated from level 1 or 2 evidence \\
4 & Expert opinion & D: Derived from level 4 evidence or extrapolated from level 2 or 3 evidence
\end{tabular}

'I fully disagree' and 10 meaning 'I fully agree'. The means and standard deviations of LoA for each item were calculated in the second and third voting round: LoA was eight or above for each item. The level of evidence and grade of recommendation (Table 1) were provided for each item. ${ }^{8}$

\section{RESULTS}

Five overarching principles and 13 recommendations were presented in Table 2. An algorithm for management of PsA was illustrated in Figure 1.

\section{Overarching principles}

A. Psoriatic arthritis is a heterogeneous and potentially severe disease, which may cause disability and require multidisciplinary follow-up and treatment. Management of musculoskeletal findings should be performed by a specialist in rheumatology or physical medicine and rehabilitation (LoA=9.80 \pm 0.69$)$.

Although the causes of PsA have not been identified clearly, genetic, immunologic, and environmental factors all contribute. ${ }^{9}$ Furthermore, PsA is a heterogeneous disease, so the assessment and management of all domains of disease, including peripheral arthritis, axial diseases, dactylitis, enthesitis and involvement of skin and nails, are essential. Multidisciplinary approach involving various physicians and other healthcare professionals may be required due to comorbidities, functional limitation, psychiatric disturbance and extra-articular manifestations such as involvement of the eye, skin, and gastrointestinal system. It is necessary to cooperate with a dermatologist in significant skin and nail involvement. PsA affects significantly the quality of life and work capacity and is associated with functional disability. ${ }^{10}$

According to previous data obtained from rheumatoid arthritis (RA), patients followed by rheumatologists are diagnosed earlier, have DMARD treatment more often and better results compared to other physicians. ${ }^{11,12}$ Early diagnosis and treatment are important for the best outcomes in patients with PsA; therefore, patients with suspected PsA should be referred to a rheumatologist or physical medicine and rehabilitation specialists as early as possible.

Due to the insufficient number of rheumatologists in our country, this task is carried out by physical medicine and rehabilitation specialists experienced in caring for patients with PsA as well as rheumatologists. Furthermore, in Turkey, rheumatology is a subspecialty after completing residency in either internal medicine or physical medicine and rehabilitation. Therefore, expert panel discussed and added physical medicine and rehabilitation specialists besides rheumatologists for our country.

B. Treatment of patients with PsA should be individualized. The treatment plan must be determined by shared decision between the patient and the physician by taking into account the disease activity, structural damage, efficacy, safety, cost, previous therapies and accompanying comorbid conditions $(\mathrm{LoA}=9.90 \pm 0.50)$.

Therapeutic decisions should be individualized considering patient preferences, disease activity, structural damage, efficacy, safety and cost of 
Table 2. Turkish League Against Rheumatism recommendations for management of psoriatic arthritis, with levels of agreement and level of evidence
Overarching principles
Levels of agreement
Levels of evidence

Mean \pm SD

A PsA is a heterogeneous and potentially severe disease, which may cause disability and may require multidisciplinary follow-up and treatment. Management of musculoskeletal findings should be performed by a specialist in rheumatology or physical medicine and rehabilitation.

$9.80 \pm 0.69$

B Treatment of patients with PsA should be individualized. The treatment plan must be determined by shared decision between the patient and the physician by taking into account the disease activity, structural damage, efficacy, safety, cost, previous therapies and accompanying comorbid conditions.

C The main purpose of treatment in patients with PsA is to maximize health-related quality of life. Therefore, control of symptoms, prevention of structural damage, improving functions and participation in social life should be aimed by abrogation of inflammation.

D Treatment and follow-up of patients with PsA; extra-articular manifestations, comorbidities such as cardiovascular diseases, metabolic syndrome, smoking and current pregnancy should be evaluated in a comprehensive manner.

E The treatment of patients with PsA should include pharmacological and non-pharmacological strategies. Patients should be informed about their disease, encouraged in cessation of smoking and getting rid of overweight. Individualized exercise, occupational therapy, physiotherapy and rehabilitation may be applied according to the clinical situations and patients' expectations.

\section{Recommendations}

1 Early diagnosis and treat-to-target (T2T) strategies should be considered in PsA, and minimal disease activity should be targeted with regular follow-up and appropriate adjustment of therapy.

2 NSAIDs may be used to improve musculoskeletal signs and symptoms in patients with PsA.

$9.40 \pm 1.09$

3 Local glucocorticoid injections should be considered as a part of the treatment in patients with PsA with peripheral arthritis, dactylitis and enthesitis. Systemic corticosteroids may be used with caution at the lowest effective dose.

4 In patients with peripheral arthritis, the initiation of csDMARDs should be considered as soon as possible, especially if there are poor prognostic factors. MTX treatment should be preferred in the presence of a psoriatic skin lesion.

5 In patients with peripheral arthritis and inadequate response or intolerance to csDMARD; biological theraphy (TNFi, IL17i, IL12/23i) or tsDMARD should be considered. In this case, the drug of first choice may be a TNFi.

6 If TNFi is preferred as a biological treatment for peripheral arthritis in patients with PsA, combination with csDMARDs may be considered.

7 In patients with peripheral arthritis and inadequate response to bDMARD targeting TNF, IL17, IL12/23 or APR; tofacitinib or abatacept may be considered.

8 In patients with enthesitis and inadequate response to NSAIDs, a bDMARD targeting TNF, IL17, IL12/23 pathway should be considered; tsDMARD may be considered in patients with still inadequate response. In this case, the drug of first choice may be a TNFi.

9 In patients with dactylitis and inadequate response to NSAIDs and csDMARDs, a bDMARD targeting TNFi, IL17, IL12/23 pathway should be considered; tsDMARD may be considered in patients with still inadequate response. In this case, the drug of first choice may be a TNFi.

10 In patients with predominantly axial disease and insufficient response to NSAIDs, a bDMARD targeting TNF, IL17, IL12/23 pathway should be considered. In this case, the drug of first choice may be a TNFi.

11 csDMARD is not recommended in patients with PsA who have predominantly axial disease.

12 In active PsA with concomitant IBD and inadequate response to a csDMARD, TNFi, particularly a mAb should be considered. If TNFi therapy fails, bDMARD targeting IL12/23 therapy may be considered.

13 In patients with inadequate response to a bDMARD, switching to another bDMARD with the same or a different mechanism of action should be considered.

SD: Standard deviation; PsA: Psoriatic arthritis; NSAID: Nonsteroidal antiinflammatory drug; csDMARD: Conventional synthetic disease-modifying antirheumatic drug; TNFi: Tumor necrosis factor inhibitor; IL: Interleukin; tsDMARD: Targeted synthetic disease-modifying antirheumatic drug; bDMARD: Biologic disease-modifying antirheumatic drug; APR: Apremilast; IBD: Inflammatory bowel disease; mAb: Monoclonal antibody. 


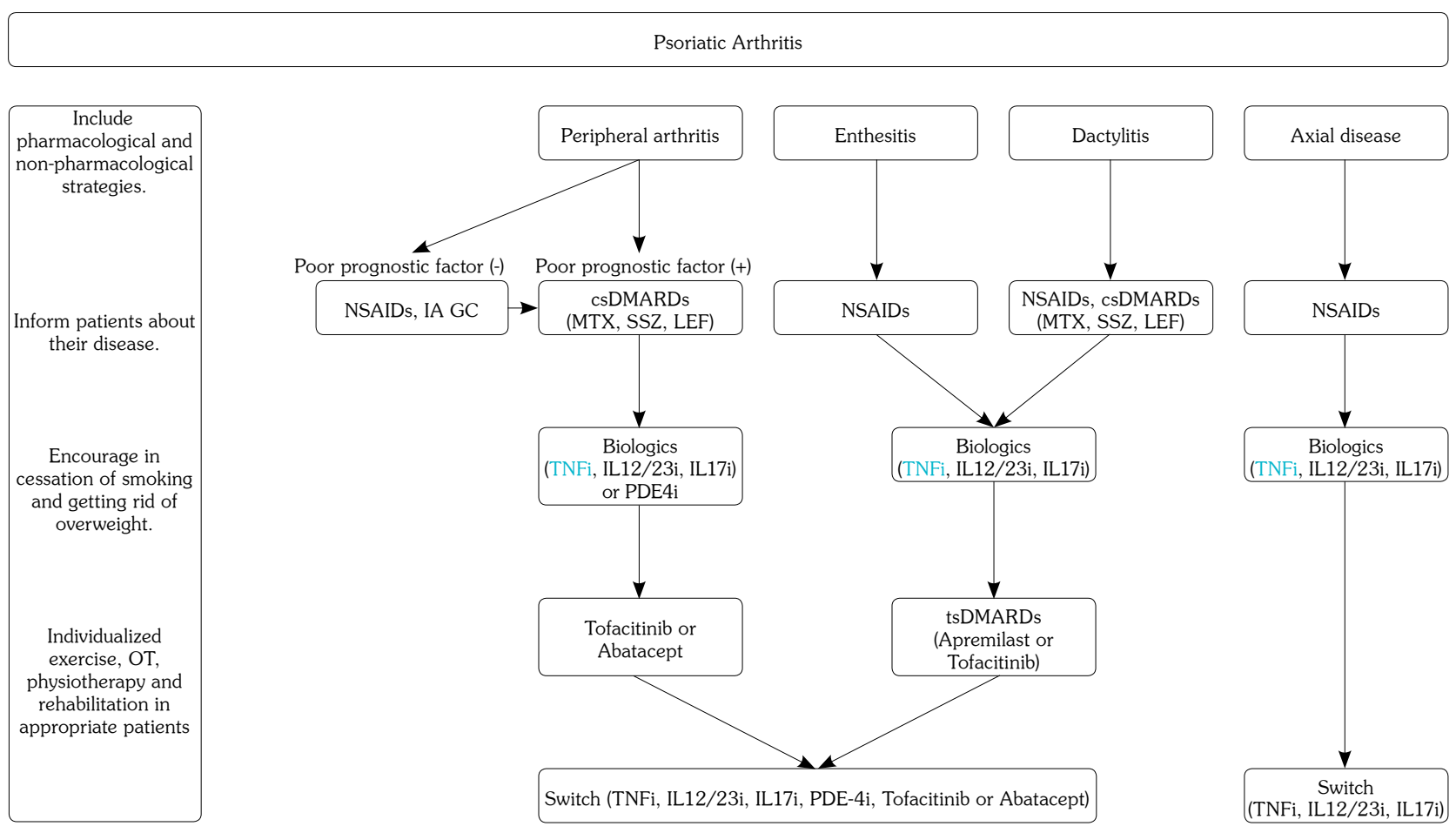

Figure 1. Turkish League Against Rheumatism algorithm for treatment of active psoriatic arthritis. csDMARDs: Conventional synthetic disease-modifying antirheumatic drugs; DMARDs: Disease-modifying antirheumatic drugs; GC: Glucocorticoid; IA: Intraarticular; IL12/23i: Interleukin 12/23 inhibitor; IL17i: Interleukin 17 inhibitor; LEF: Leflunomide; MTX: Methotrexate; NSAIDs: Nonsteroidal antiinflammatory drugs; OT: Occupational therapy; PDE-4i: Phosphodiesterase 4 inhibitor; SSZ: Sulfasalazine; TNFi: Tumor necrosis factor inhibitor; tsDMARDs: Targeted synthetic DMARDs.

the treatment, and previous therapies and accompanying comorbid conditions. The patient must be properly informed about the benefits and risks of therapeutic options when treatment is given to enhance the treatment compliance and success. ${ }^{13}$ In a study from DANBIO registry, authors assessed the frequency of discordance in patient's and physician's global assessment in patients with RA, axial spondyloarthritis (axSpA), and PsA. ${ }^{14}$ The frequency of discordance in this study was high between patients and their physicians (patient global assessment was $>20 \mathrm{~mm}$ higher than physician global assessment). This may cause difficulties in shared decision process; therefore, patients' education is essential. Although there was a good correlation between various disease activity measures, physicians usually evaluated the disease activity of PsA lower with respect to patients. ${ }^{15}$ Hence, incorporating patient reported outcome measures is necessary to assess disease activity in PsA. Generally, in patients with mild symptoms and without radiological damage or functional impairment, the low-cost way to relieve symptoms is initiating a nonsteroidal antiinflammatory drug (NSAID) rather than starting a DMARD. However, in patients with poor prognostic factors or poor response to a csDMARD, biologics may be a preferred treatment. A recent study evaluating rheumatologists' drug choice has shown that rheumatologists consider the economic aspects and the patient's preferences in addition to their efficacy when deciding on drugs. ${ }^{16}$ Ideally, patients should be reviewed promptly, offered regular evaluation by appropriate specialists, and have treatment adjusted as needed in order to achieve the goals of therapy. In addition, qualified specialists should regularly assess patients and proper treatment adjustment should be performed to achieve the goals of therapy.

Expert panel decided to add 'individualization' of treatment in PsA according to patient preferences, disease activity, structural damage, efficacy, safety and cost of the treatment, as well as previous therapies and accompanying comorbid conditions. 
C. The main purpose of treatment in patients with PsA is to maximize healthrelated quality of life. Therefore, control of symptoms, prevention of structural damage, improving functions and participation in social life should be aimed by abrogation of inflammation ( $L o A=9.90 \pm 0.50)$.

Psoriatic arthritis is related with poor physical function, health-related quality of life and long-term work disability. ${ }^{17-19}$ All of these may be associated with comorbidities, duration and severity of disease, response to therapy, and socioeconomic factors. If these factors are modified with targeted interventions, functions and health-related quality of life may potentially improve in patients with PsA. Since inflammation in PsA is associated with the progression of radiological damage, the abrogation of inflammation is a component of the therapeutic objective and needed to achieve good outcomes. ${ }^{20-25}$

D. Treatment and follow-up of patients with PsA; extra-articular manifestations, comorbidities such as cardiovascular diseases, metabolic syndrome, smoking and current pregnancy should be evaluated in a comprehensive manner (LoA=9.70 \pm 0.83$)$.

Patients with PsA may present with a wide spectrum of clinical manifestations including axial involvement, peripheral arthritis, and extraarticular features (uveitis, psoriasis, inflammatory bowel disease [IBD]). Also, these patients have an increased risk of comorbidities including cardiovascular disease, metabolic syndrome, obesity, diabetes, fatty liver disease, IBD, ophthalmic disease, renal disease, osteoporosis, depression, and anxiety. ${ }^{26-28}$ Optimal treatment approach should always be aimed at improving all manifestations of the disease: in daily practice, this can be achieved by screening comorbidities, extra-articular involvement and smoking before starting treatment in PsA.

Recent studies have reported that the majority of patients with PsA have stable or low disease activity as well as better skin outcome during pregnancy. ${ }^{29}$ Patients with low disease activity before conception were shown to have more favorable outcomes during pregnancy. Thus, in pregnant patients with PsA, optimal treatment should be regulated according to the safety of the fetus and maternal disease control as well as disease activity.

During the expert meeting, vaccination was also discussed for patients with PsA. Screening for latent tuberculosis and hepatitis $B$ virus infection is recommended before starting any tumor necrosis factor inhibitor (TNFi). Although TNFis were not demonstrated to reduce efficacy of non-live vaccines, some studies demonstrated reduced or impaired response to non-live vaccines. ${ }^{30-34}$ Live-virus vaccines may contraindicate in patients receiving biologics. Optimal time to vaccinate patients with live vaccines is four weeks before starting biologics or tofacitinib, or at least one month after discontinuation of such therapy. ${ }^{35}$ The expert committee stated that there is no need to delay biological treatments for inactivated, conjugated or toxoid vaccines in patients with active PsA in the presence of indications; it is suggested that biological treatments may be delayed if liveattenuated vaccines are administered.

E. The treatment of patients with PsA should include pharmacological and nonpharmacological strategies. Patients should be informed about their disease, encouraged in cessation of smoking and getting rid of overweight. Individualized exercise, occupational therapy, physiotherapy and rehabilitation may be applied according to the clinical situations and patients' expectations $(\mathrm{LoA}=9.70 \pm 0.83)$.

In addition to pharmacological therapy, nonpharmacological treatment strategies, which are extremely important in the treatment of patients with PsA, should be a part of the therapeutic regimen. Patient education is the mainstay of non-pharmacological therapy. Patient education on treatment objectives, proper use of their medications, comorbidities associated with the disease, and joint protection has been included in the overarching principles for PsA.

Smoking appears to play a major role in the pathogenesis of several rheumatic diseases including systemic lupus erythematosus, RA, and ankylosing spondylitis (AS). Recent evidence has shown that smoking has negative effects on the skin involvement, disease activity, treatment response, and disease progression as well as the outcomes of rheumatic diseases. ${ }^{36}$ In patients with PsA, previous studies have suggested that there 
is an established association between smoking and poorer functional outcome, ${ }^{37}$ with worse self-reported health status. ${ }^{38}$ Moreover, due to the high risk of cardiovascular disease in PsA, smoking may accelerate the risk of atherosclerosis in these patients. Therefore, all patients with PsA should be warned about smoking cessation.

Fat tissue is a source of many of the same inflammatory cytokines, including tumor necrosis factor-alpha (TNF- $\alpha$ ), interleukin 6 (IL6), and IL1 beta, produced by inflamed tissue in overweight/ obese patients with inflammatory arthritis. ${ }^{39}$ Obesity is well-known to cause higher risk for cardiovascular diseases and metabolic syndromes, which have already increased with PsA. Moreover, obesity has been recently shown to be associated with more severe skin problems, higher disease activity and poor response to TNFis. A recent prospective analysis has suggested that weight loss may improve clinical outcome measures including erythrocyte sedimentation rate, $\mathrm{C}$-reactive protein (CRP), Visual Analog Scale (VAS), global VAS, Health Assessment Questionnaire (HAQ) as well as response to TNFis in patients with PsA treated with anti-TNF drugs. ${ }^{40}$ Expert committee has recommended that weight loss should be encouraged in all overweight/obese patients with PsA as a lifestyle modification.

Although there is no strong evidence for the use of physiotherapy modalities and rehabilitation programs in the managementPsA, a beneficialeffect of physical therapy and rehabilitation programs on physical function and quality of life has been demonstrated in several rheumatic diseases. ${ }^{41,42}$ International and national recommendations for the treatment of axSpA and AS suggest that physical therapy and exercises are essential for the management of these diseases. ${ }^{43,44}$ In a very recent $\mathrm{RCT}$, it has been reported that a resistance exercise program improves functional capacity of patients with PsA. ${ }^{45}$ According to extensive clinical experience, rehabilitation programs may improve physical, psychological and social functioning in patients with PsA. Therefore, the expert panel has recommended that all patients should be encouraged to participate in individualized exercise programs depending on the clinical situations and patients' expectations, and referred for occupational therapy, physical therapy and rehabilitation.

\section{Recommendations}

1. Early diagnosis and treat-to-target (T2T) strategies should be considered in PsA, and minimal disease activity should be targeted with regular follow-up and appropriate adjustment of therapy (LoA=9.50 \pm 1.02$)$.

The course of PsA is heterogeneous, and PsA significantly affects the quality of life and work capacity while being associated with functional disability. ${ }^{10}$ Early control of inflammation in PsA leads to improved long-term outcomes. Besides, patients with shorter PsA duration had greater improvements in arthritis scores and several patients reported outcome measures with etanercept treatment. ${ }^{46}$ In early PsA, short delay between onset of symptoms and diagnosis, preserved function, and male sex were the most important predictors of good clinical outcome at five-year follow-up in a study. ${ }^{22}$ In PsA, structural damage has significant effects on physical function. ${ }^{47}$ Even a six-month delay from symptom onset to the first visit with a rheumatologist contributes to the development of peripheral joint erosions and worse long-term physical function. ${ }^{48}$ Magnetic resonance imaging and ultrasonography are useful for early diagnosis of PsA. ${ }^{49}$

New treatment options have led to significant improvements in treatment strategies for PsA. Definitely, a "treat-to-target" approach has been proposed for PsA, following its successful application in RA. ${ }^{4,50,51}$ This target is accepted as remission, or if remission cannot be achieved, a low disease activity state by EULAR recommendations for PsA and the international treat-to-target task force for SpA and PsA. ${ }^{4,52}$ Remission is defined as the absence of clinical and laboratory evidence of significant inflammatory disease activity. Although the GRAPPA does not exactly recommend a treatment target, they have proposed that the final goal of therapy should be to reach the lowest possible level of disease activity in all domains of disease. ${ }^{5}$ Although there is much evidence that achieving remission leads to better structural and functional outcomes in RA, there are limited data regarding treatment objectives and remission in PsA. ${ }^{50,53-56}$ In addition, it should be noted that remission of inflammation may not be associated with the complete absence of all PsA symptoms. Furthermore, remission may be difficult to attain in 
many patients by its most stringent definition, and remission is still insufficiently defined in PsA. ${ }^{57-59}$ There are several composite measures used in PsA, some of which focusing only on arthritis while others containing various aspects of psoriatic disease. ${ }^{60}$ Recently, GRAPPA-Outcome Measures in Rheumatology Clinical Trials (OMERACT) published consensus-based recommendations and research agenda for use of composite measures and treatment targets in PsA. ${ }^{60}$ The group agreed that several composite measures may be used in PsA since there was no consensus on composite measures. Additionally, the group recommended a treatment target of very low disease activity or minimal disease activity (MDA).

There is no consensus on the best measures of disease activity in PsA. Primary endpoint of several studies is RA-derived American College of Rheumatology (ACR) response criteria and sometimes disease activity score-28 joint. Since PsA is a complex disease with both articular and extra-articular manifestations, several composite measures of disease activity, which cover multiple domains, have been developed for PsA. ${ }^{61-65}$ MDA is a simple, easy-to-use index, and a state of disease activity in PsA rather than a continuous measure. ${ }^{66,67} \mathrm{MDA}$ in PsA has been defined as five of the seven criteria including musculoskeletal and skin manifestations and patient-reported outcomes. Remission is possible in PsA, but sometimes not for long periods. ${ }^{58}$ Here, we preferred MDA as a treatment target for PsA instead of remission since achieving remission may be difficult and remission has been defined insufficiently and is not a sustainable target.

There is no clear definition for the best interval for patient monitoring. EULAR 2015 suggests regular monitoring. EULAR recommends that those with active disease should be seen from monthly to every three months, and if needed, treatment should be adjusted appropriately. ${ }^{4}$ According to the TIght COntrol of Psoriatic Arthritis (TICOPA) trial, tight control (four weekly reviews) provided more favorable outcomes than standard care (12 weekly reviews). ${ }^{51,68}$ Since there is no consensus on the monitoring interval, we recommended four weekly reviews for active disease as EULAR. The OMERACT updated PsA core domain set in 2016 meeting. ${ }^{69}$ The recommended core set for the assessment of PsA includes musculoskeletal disease activity, skin disease activity, fatigue, pain, patient global assessment, physical function, health related quality of life and systemic inflammation. ${ }^{69}$

2. Nonsteroidal antiinflammatory drugs may be used to improve musculoskeletal signs and symptoms in patients with PsA. Potential side effects should be considered (LoA=9.40 \pm 1.09 ).

There are limited data on the efficacy of NSAIDs in PsA. NSAIDs are effective on joint symptoms, despite no efficacy on skin lesions..$^{70-72}$ Potential side effects of NSAIDs on gastrointestinal and cardiovascular systems should be taken into account when prescribing NSAIDs. ${ }^{71,73}$ EULAR encourages the use of NSAIDs with the lowest dose and the shortest treatment duration, due to their potential side effects. There is no evidence that NSAIDs increase skin lesion.

\section{Local glucocorticoid injections should} be considered as a part of the treatment in patients with PsA with peripheral arthritis, dactylitis and enthesitis. Systemic glucocorticoids may be used with caution at the lowest effective dose $(\operatorname{LoA}=9.10 \pm 1.59)$.

Intra-articular glucocorticoid injection is effective in PsA. ${ }^{74}$ Glucocorticoid injection into inflamed sacroiliac joints is also a useful, effective and safe therapy for isolated sacroiliitis in patients with SpA. ${ }^{75,76}$ Glucocorticoid injection of the sacroiliac joint may be performed by computed tomography, magnetic resonance imaging (MRI), fluoroscopy or ultrasound guided. ${ }^{75-77}$ Local or systemic glucocorticoids may have some beneficial effects in patients with dactylitis and enthesitis. ${ }^{4,5,74,78}$

There is no data from RCTs on the systemic use of glucocorticoids in PsA. Dermatologists avoid the systemic use of glucocorticoids because of the potential adverse effects on the current psoriatic skin lesions and the rapid exacerbation of skin lesions after withdrawal of glucocorticoids. ${ }^{79-81}$ In a retrospective evaluation of 104 patients, 38\% of patients had history of systemic glucocorticoid use before the onset of pustular psoriasis and at least one third of these cases were apparently precipitated by the withdrawal of systemic corticosteroid therapy. ${ }^{79}$

Flare of psoriatic skin lesions after glucocorticoid withdrawal is not confirmed by evidence in rheumatology practice; nevertheless, 
long-term use should be avoided due to potential side effects of systemic glucocorticoids. ${ }^{82}$ Systemic glucocorticoids are widely used usually at low doses in patients with PsA in rheumatology clinics. ${ }^{83}$ Locally or systemically used glucocorticoids seem to be useful at least for some patients with PsA. ${ }^{84}$ Glucocorticoids, either locally or systemically, are recommended for PsA by EULAR and GRAPPA, at low doses (usually $\leq 7.5 \mathrm{mg} /$ day) and for short periods, to reduce adverse effects. ${ }^{4,5}$

\section{In patients with peripheral arthritis, the initiation of csDMARDS should be considered as soon as possible, especially if there are poor prognostic factors. Methotrexate (MTX) treatment should be preferred in the presence of a psoriatic skin lesion $(\mathrm{LoA}=9.70 \pm 0.83)$.}

There is limited evidence from RCTs regarding use of csDMARDs in peripheral arthritis. Peripheral arthritis is defined as one or more tender and swollen joints. ${ }^{4}$ DMARDs are recommended because of their low cost, ease of access, and lack of evidence that a short delay in the initiation of more effective treatments will affect long-term function and quality of life in patients with peripheral arthritis. ${ }^{5}$ Real-life retrospective analysis of csDMARDs used in PsA demonstrated that all three DMARDs (methotrexate, sulfasalazine [SSZ] and leflunomide) improved Bath Ankylosing Spondylitis Disease Activity Index (BASDAI), Bath Ankylosing Spondylitis Functional Index, wellbeing, and treatment effect in a cohorts. ${ }^{85}$ The experts of EULAR considered that patients with peripheral arthritis and poor prognosis should be promptly started on csDMARDs, and also those with milder disease if arthritis persisted despite NSAID therapy and glucocorticoid injections. ${ }^{4}$ Although GRAPPA strongly recommends both csDMARDs and TNFi in DMARD-naive patients with peripheral arthritis, this group also indicated that DMARDs might be used first in many cases, but consideration should be given to early escalation of therapy, particularly in patients with poor prognostic factors. ${ }^{5}$

Psoriatic arthritis is a complex disease, and natural history and clinical manifestations are variable. Some of the clinical manifestations are important for prediction of destruction and disease course. Poor prognostic factors were described by EULAR according to evidence as follows; actively involved $\geq 5$ tender or swollen joint; radiographic damage; elevated acute phase reactants; and extraarticular manifestations. ${ }^{20,86-89}$ Early csDMARD therapy was recommended if any of the poor prognostic factors was present. ${ }^{4}$ There are several studies published recently showing that outcomes are worse if the diagnosis or the initiating of a csDMARD is delayed. ${ }^{22,46,48,90}$ Enthesitis and dactylitis are associated with greater disease burden of PsA, and successful treatment of these peri-articular manifestations is important. ${ }^{89}$

Despite the relative lacking data from RCTs, the experts from EULAR recommended MTX as the first-choice csDMARD based on the available literature. ${ }^{4}$ Recently, a multicenter RCT in the United Kingdom assessed the use of MTX in PsA for six months. MTX reduced only patient's and physician's global scores and skin scores at six months. This RCT did not find any evidence for MTX improving synovitis in PsA. ${ }^{91}$ Nevertheless, MTX is widely used and has good retention rate in PsA. In a real-life study, MTX treatment improved disease activity and health-related quality of life in patients with PsA after six months of treatment. Two-year retention rates of MTX therapy in patients with PsA were $65 \%$ and similar with RA. ${ }^{92}$ Furthermore, $22 \%$ of patients with PsA who were treated with MTX alone achieved MDA in TICOPA trial. ${ }^{51}$ MTX is the most frequently used csDMARD in the treatment of psoriasis. Given the demonstrated efficacy of MTX on skin involvement, MTX is specifically mentioned as the preferred option in patients with clinically 'relevant' psoriasis. ${ }^{93}$

Some of the panelists suggested starting DMARD to each patient with peripheral arthritis with or without poor prognostic factor as an expert opinion. It is not clear when structural damage will occur in the presence of active peripheral arthritis before the initiation of csDMARDs. Therefore, as in EULAR, our expert panel decided that patients with peripheral arthritis and poor prognosis should be promptly started on csDMARDs.

5. In patients with peripheral arthritis and inadequate response or intolerance to csDMARDs; biological theraphy (TNFi, IL17inhibitor [IL17i], IL12/23i) or tsDMARD should be considered. In this case, the drug of first choice may be a TNFi $($ LoA $=9.30 \pm 1.35)$. 
In patients with peripheral arthritis who have inadequate response to a csDMARD, a bDMARD is usually indicated. There is sufficient evidence to show that TNFi is effective and safe in the treatment of PsA as a first-line biologic. Most experiences with biologics in PsA therapy have been accumulated in the use of TNFi. Otherwise, a different targeted biologic may be required in patients with an inadequate response to TNFi. Although GRAPPA recommends either csDMARDs or TNFi as a first-line therapy in peripheral arthritis, EULAR recommends bDMARDs after inadequate response or intolerance to csDMARDs.

After the presentation of EULAR and GRAPPA recommendations, more bDMARDs and tsDMARDs have shown efficacy in PsA, and some have been approved by the Food and Drug Administration (FDA) for treatment of PsA. The expert committee decided to combine EULAR's $5^{\text {th }}, 6^{\text {th }}$ and $7^{\text {th }}$ recommendations in one item, because there is sufficient evidence that new treatment options are effective in patients with either csDMARD naïve or inadequate response. Furthermore, abatacept and tofacitinib were also approved for the treatment of PsA; however, we mentioned them in the $7^{\text {th }}$ recommendation.

The efficacy of TNFi have been demonstrated for joint involvement and in preventing the progression of radiographic damage in PsA. ${ }^{94-}$ 96 Ustekinumab (IL12/23i), secukinumab (IL7i), ixekizumab (IL7i) and apremilast (APR) (phosphodiesterase [PDE]-4i) were approved by FDA for the treatment of active PsA, after the efficacy and safety have been demonstrated in a recent $\mathrm{RCT} .{ }^{96-106}$ The efficacy of these DMARDs was demonstrated in patients with inadequate response to either csDMARD or TNFi. Therefore, all of the bDMARDs or tsDMARDs may be considered to be the first line therapy in patients with inadequate response to csDMARDs. On initiation of a new treatment, it must be noted that there are no available data on the impact of $\mathrm{PDE}-4 \mathrm{i}$ on radiographic damage, in contrast to TNFi, IL12/23i, and IL17i. APR should not be used in patients with erosive disease, because the capacity of APR to prevent joint damage has not been established in PsA. APR may be particularly suitable for patients who avoid csDMARD therapy, infusion or injections. As in the EULAR recommendations, we discussed and decided that the TNFi treatment would be the first choice after inadequate response or intolerance to csDMARDs, due to the long-term experience in clinical practice, well-established efficacy and acceptable safety profile and high retention rate over time in PsA.

In our country, Turkish Medicines and Medical Device Agency (TMMDA) approved six TNFis (infliximab, etanercept, adalimumab, golimumab, certolizumab, and biosimilar infliximab), secukinumab and ustekinumab for treatment of PsA and APR may be used off-label for PsA in Turkey.

\section{If TNFi is preferred as a biological treatment for peripheral arthritis in patients with PsA, combination with csDMARDs may be considered $(L o A=9.30 \pm 1.53)$.}

Recent evidence has highlighted that immunogenicity or development of antidrug antibodies plays a major role in shorter drug survival, therapeutic failure and loss of clinical response to TNFi particularly in monoclonal antibodies (mAbs) over time in patients with RA. ${ }^{107-109}$ In certain cases, immunogenicity also leads to several adverse drug reactions including infusion-related reactions, bronchospasm, or thromboembolic events. ${ }^{110-112}$ Accumulating data advocate co-administration of csDMARD therapy with TNFi in patients with RA. More recently, co-administration of csDMARD therapy is recommended for the treatment of RA by EULAR. ${ }^{113}$ In contrast to RA, in cases with PsA, the role of use of concomitant MTX has not been clarified due to limited evidence from registries.

A recent systematic review of the literature comparing TNFi monotherapy with combination therapy with MTX from six registries of PsA revealed little or no improvement efficacy with the combination over TNFi monotherapy, although drug survival of $\mathrm{mAb}$ with combined treatment was superior. ${ }^{114}$ On the other hand, some data suggest that concomitant use of MTX with TNFi may improve skin outcome, drug survival, and clinical efficacy and also reduce the risk of infusion reaction by reducing immunogenicity in patients with psoriasis and PsA. ${ }^{115-118}$ Expert opinion supports that patients with PsA with peripheral arthritis receiving TNFi, particularly $\mathrm{mAb}$, should also continue using csDMARD. 
7. In patients with peripheral arthritis and inadequate response to bDMARD targeting TNF, IL17, IL12/23 or APR; tofacitinib or abatacept may be considered $(\mathrm{LoA}=8.65 \pm 1.80)$.

The role of $\mathrm{T}$ lymphocyte in the pathogenesis of psoriasis and PsA is well-recognized. ${ }^{119,120}$ Activated $\mathrm{T}$ lymphocytes are present in inflamed joints of the patients with $\mathrm{PsA}^{121}$ and reduced by abatacept. ${ }^{122}$ The efficacy of abatacept was assessed in two RCTs in 594 adult patients with disease duration of more than seven years. ${ }^{123,124}$ Patients had active PsA ( $\geq 3$ swollen joints and $\geq 3$ tender joints) despite prior treatment with DMARD therapy and had one qualifying psoriatic skin lesion of at least $2 \mathrm{~cm}$ in diameter. The primary endpoint for both RCTs was the ACR20 response at week 24 . In phase 2 , trial of abatacept, 170 patients with an inadequate response to a csDMARD (60\% MTX) or a biologic agent (37\% TNFi) were enrolled; an ACR20 response was achieved in $48 \%$ of PsA. Abatacept improved MRI, HAQ, short form-36, and Psoriasis Area and Severity Index scores. ${ }^{123}$ Efficacy and safety of abatacept were analyzed in a phase $3 \mathrm{RCT}$ in 424 patients with active PsA and plaque psoriasis who had an inadequate response or intolerance to at least one csDMARD. ${ }^{124}$ About $60 \%$ had prior exposure to a TNFi. ACR20 response was achieved in 39.4\% of patients receiving abatacept at week 24 . The effects on psoriatic skin lesions were modest. Abatacept was well-tolerated and the frequency of adverse effects was similar in the treatment and control groups. ${ }^{124}$

Tofacitinib is an oral inhibitor of Janus kinase (3 and 1), and its efficacy has been demonstrated in several RCTs in patients with PsA with an inadequate response to a csDMARD and TNFi. ${ }^{125-127}$ Oral Psoriatic Arthritis TriaL (OPAL) Broaden enrolled 422 patients with PsA who had failed to respond to previous treatment with csDMARDs, ${ }^{125}$ and OPAL Beyond involved 395 patients with PsA who had inadequate response to a TNFi. ${ }^{126}$ In OPAL Broaden trial, patients were randomly assigned to tofacitinib $(5 \mathrm{mg}$ twice daily or $10 \mathrm{mg}$ twice daily), adalimumab (40 mg subcutaneously every 2 weeks), or placebo groups. Primary endpoint was the proportion of patients who had an ACR20 response at month three. ACR20 response rates at month three were 50\% in the $5 \mathrm{mg}$ tofacitinib group, $61 \%$ in the $10 \mathrm{mg}$ tofacitinib group, and $52 \%$ in the adalimumab group. Physical function was also improved at three months measured by HAQ-disability index. The rate of adverse events through month 12 was similar in tofacitinib and adalimumab groups $166 \%$ with $5 \mathrm{mg}$ tofacitinib, $71 \%$ with $10 \mathrm{mg}$ tofacitinib, and $72 \%$ with adalimumab). ${ }^{125}$

In OPAL Beyond trial, patients were randomly assigned to tofacitinib (5 $\mathrm{mg}$ or $10 \mathrm{mg}$ twice daily), or placebo groups (with a switch to $5 \mathrm{mg}$ or $10 \mathrm{mg}$ of tofacitinib twice daily at three months). ACR20 response rates at month three were 50\% in the $5 \mathrm{mg}$ tofacitinib group, $47 \%$ in the $10 \mathrm{mg}$ tofacitinib group, and $24 \%$ in the placebo group. Greater improvements in physical function at three months were also observed with tofacitinib. Adverse effects with tofacitinib were similar to those seen in other trials in patients with RA or psoriasis. $^{126}$

After recent RCTs, abatacept and tofacitinib have been approved by FDA for the treatment of active PsA in 2017. Both abatacept and tofacitinib are effective in patients with PsA with inadequate response to csDMARDs and TNFi. Even if Turkish Medicines and Medical Device Agency (TMMDA) have not approved the use of abatacept and tofacitinib in PsA yet, both are used off-label in PsA in Turkey. Although we have sufficient experience with the use of abatacept and tofacitinib in patients with RA, we have limited experience in patients with PsA. Due to accumulating evidence from RCTs, expert panel has recommended abatacept and tofacitinib in patients with PSA with inadequate response to csDMARDs or bDMARDs.

8. In patients with enthesitis and inadequate response to NSAIDs, a bDMARD targeting TNF, IL17, IL12/23 pathway should be considered; tsDMARD may be considered in patients with still inadequate response. In this case, the drug of first choice may be a TNFi (LoA=9.30 \pm 1.15$)$.

In patients with enthesitis, initial treatment is mostly NSAIDs based on expert opinion; however, local glucocorticoids and physical therapy are sometimes useful in patients with PsA. Efficacy of physiotherapy has not been published. If these treatments fail to control the inflammation, particularly in those with functional limitation 
or decreased quality of life due to enthesitis, biologics are suggested as therapy instead of csDMARDs. $^{72,128}$ Although data from RCTs are lacking, in one study, SSZ was not effective on enthesitis, and the efficacy of other csDMARDs has not been demonstrated in placebo-controlled studies. $^{72,128,129}$ bDMARDs used for peripheral arthritis have also been reported to be effective for enthesitis in trials. ${ }^{72}$ TNFis are effective on enthesitis according to several RCTs. ${ }^{72,128,130-132}$ There is high-quality evidence of the effectiveness of ustekinumab, secukinumab, and APR for enthesitis in PsA. ${ }^{72,97,98,105,128,133}$ Furthermore, ixekizumab, another biologic targeting the IL17 pathway, has been shown to be effective on enthesitis resolution. ${ }^{99}$

Thus, expert panel stated that the first drug of choice might be a TNFi due to the accumulated experience in patients with enthesitis and inadequate response to NSAIDs.

9. In patients with dactylitis and inadequate response to NSAIDs and csDMARDs, a bDMARD targeting TNFi, IL17, IL12/23 pathway should be considered; tsDMARD may be considered in patients with still inadequate response. In this case, the drug of first choice may be a TNFi $(\operatorname{LoA}=9.50 \pm 1.02)$.

Dactylitis, a clinical feature of PsA, may also be a severity marker for PsA. Dactylitis may respond to NSAIDs and some traditional DMARDs. Unlike enthesitis, csDMARDs have been proposed as a treatment for dactylitis, based on limited data for this indication. ${ }^{5}$ If it is severe, biological DMARDs are usually indicated as in patients with dactylitis, since improvements were reported as secondary outcomes in RCTs of these agents. ${ }^{134}$ In a recent systematic review, ustekinumab, certolizumab, and infliximab are suggested as therapy in patients with dactylitis according to the effect sizes. ${ }^{134}$ In a RCT, dactylitis score at week 24 was significantly improved with APR $30 \mathrm{mg}$, and this sustained therapeutic effect of APR was observed through week 52 in patients continuing therapy. ${ }^{105}$ Secukinumab showed sustained efficacy across multiple domains of PsA through week 104, including disease activity, quality of life, physical function, skin symptoms, dactylitis, and enthesitis. ${ }^{97,98}$ Furthermore, ixekizumab has been shown to be effective on dactylitis resolutions..$^{99,100}$
Given the lack of studies comparing the efficacy of the bDMARDs and APR in patients with dactylitis who did not respond to the first line of therapy, each of these drugs may be used as first line therapy. However, expert panel has stated that the drug of first choice may be a TNFi due to the accumulated experience in patients with dactylitis and inadequate response to NSAIDs or csDMARDs.

10. In patients with predominantly axial disease and insufficient response to NSAIDs, a bDMARD targeting TNF, IL17, IL12/23 pathway should be considered. In this case, the drug of first choice may be a TNFi (LoA $=9.70 \pm 0.83)$.

Mild symptoms may be successfully treated with a NSAID in axial disease, while patients with moderate to severe symptoms or those who are resistant to NSAIDs are usually treated with a bDMARD targeting TNF, IL17, IL12/23 pathway. Nevertheless, due to the lack of specific studies in patients with axial PsA, the treatment recommendations for axial disease are derived from response to therapy in AS. ${ }^{4,5}$ In PsA trials, some patients were classified as having predominant axial diseases. TNFis are highly effective in AS and non-radiographic-axSpA to decrease disease activity and improve quality of life. ${ }^{135,136}$

Although there is no direct evidence of axial disease in PsA, RCTs have shown that secukinumab provides a clear benefit when compared to placebo in patients with AS. ${ }^{137-140}$ Signs and symptoms of AS improved through two years of therapy and a low mean progression of spinal radiographic changes occurred with secukinumab. ${ }^{138}$ There are limited data supporting the use of the IL12/23i ustekinumab in patients with spondylitis; the trials have generally been limited to patients with AS. The patients treated with ustekinumab showed a significant BASDAI response not only in the patients with axial involvement but also in the whole PsA patients' group. ${ }^{141}$ Recently, a posthoc analysis of PSUMMIT 1 and 2 studies focusing on the PsA patients with physicianreported spondylitis has been published. ${ }^{111}$ In this spondylitic subset, ustekinumab-treated patients achieved significantly more BASDAI 20/50/70 response and Ankylosing Spondylitis Disease Activity Score-CRP improvement than placebo. 
11. Conventional synthetic DMARD is not recommended in patients with PsA who have predominantly axial disease $(\mathrm{LoA}=8.90 \pm 1.63)$.

The treatment options for axial disease of PsA are derived mostly from AS since these data are not available for axial PsA. For patients with axial symptoms that have not responded to NSAIDs, physiotherapy, or sacroiliac joint injections, initiation of TNFi is recommended; DMARDs are not effective for the treatment of diseases in this domain. ${ }^{5}$ Assessment of SpondyloArthritis International Society-EULAR does not recommend the use of csDMARDs for purely axial disease. ${ }^{43}$ There is no available evidence on the efficacy of SSZ in axial disease within AS or PsA. ${ }^{142}$ csDMARDs are widely used in PsA, but few trials are available about their effects on axial disease, which are not regularly assessed as a main outcome in clinical trials, and there is no beneficial effect on axial disease of PsA. ${ }^{143,144}$ However, available evidence for the combination of csDMARD indicates a lack of any significant benefit on axial symptoms; thus, this treatment approach does not represent an effective alternative to TNFi therapy. ${ }^{144}$ Herewith, expert panel wants to emphasize that "csDMARD is not recommended in patients with predominantly axial disease' as a separate item.

12. In active PsA with concomitant IBD and inadequate response to a csDMARD, TNFi, particularly a mAb should be considered. If TNFi therapy fails, bDMARD targeting IL12/23 therapy may be considered $(\mathrm{LoA}=9.00 \pm 1.61)$.

Patients with psoriasis are 3.8 to 7.5 times more likely to have IBD than general population. ${ }^{145}$ Recent data have demonstrated that psoriasis, particularly with concomitant PsA, had a significantly increased risk of Crohn's disease (CD). ${ }^{146}$ Currently, mAbs including infliximab, adalimumab, certolizumab, and golimumab are widely accepted as efficacious therapies for inducing and maintaining remission in the treatment of IBD. ${ }^{147-151}$ In addition, etanercept has shown no efficacy in IBD. Therefore, the expert panel recommended that treatment with TNFi, particularly mAb, should be considered in patients with active PsA and concomitant IBD.
More recently, IL12/23 immune pathway has received great attention for the treatment of patients with PsA as well as IBD. In patients with moderate to severe Crohn's disease who are primary non-responders or intolerant to TNFi therapy, ustekinumab has been shown to have significantly higher clinical response as compared with placebo. ${ }^{152}$ Therefore, in patients with active PsA with concomitant IBD despite treatment with TNFi mAb, an IL12/23i therapy should be considered as an effective therapeutic option.

To our knowledge, there is no clinically meaningful efficacy data about the use of IL17i therapy in patients with active IBD; $;^{153}$ therefore, this agent should not be considered primarily in the treatment of IBD in patients with PsA.

\section{In patients with inadequate response} to a bDMARD, switching to another bDMARD with the same or a different mechanism of action should be considered (LoA=9.70 \pm 0.83).

In biologic treatment, when failure occurs due to either adverse events or inadequate response, switching to an alternative biologic agent with the same or a different mechanism of action is recommended by EULAR and GRAPPA. Most data on TNFi switching in patients with PsA come from registries. ${ }^{86-88}$ These registries showed that the second TNFi was less efficacious than the first and the third less than the second. ${ }^{154-156}$ Recent RCTs indicated that biologics were effective in patients with PsA who have failed treatment previously with one or more biologic agents. ${ }^{98,101,104,126,132,157,158}$ Efficacy of switching from TNFi to ustekinumab, secukinumab, ixekizumab, APR, tofacitinib and abatacept has been demonstrated in recent $\mathrm{RCTs}$. Patients included in these studies were unresponsive to DMARDs or TNFi. The response rates were lower in patients with previous exposure to TNFi than in the TNF-naïves. However, data regarding switching between new DMARD or new DMARDs to TNFi is lacking. The choice of switching to another drug should be made according to previous therapy, drug's safety profile, and patients' comorbidities and preferences. Data suggest that a second TNFi (after failure of the first TNFi) can still be efficacious, although the level of efficacy may be lower than with the first TNFi. 
In conclusion, this is the first paper that summarizes the recommendations of TLAR as regards the treatment of PsA. With a level of agreement greater than eight for each item, these opinions were based on the current guidelines and accumulating data in the literature. We believe that this paper provides Turkish physicians dealing with PsA patients a practical guide in their routine clinical practice.

\section{Declaration of conflicting interests}

The authors declared no conflicts of interest with respect to the authorship and/or publication of this article.

\section{Funding}

The authors received no financial support for the research and/or authorship of this article.

\section{REFERENCES}

1. Elyoussfi S, Thomas BJ, Ciurtin C. Tailored treatment options for patients with psoriatic arthritis and psoriasis: review of established and new biologic and small molecule therapies. Rheumatol Int 2016;36:603-12.

2. Smolen JS, van der Heijde D, Machold KP, Aletaha $\mathrm{D}$, Landewé R. Proposal for a new nomenclature of disease-modifying antirheumatic drugs. Ann Rheum Dis 2014;73:3-5.

3. Ritchlin CT, Kavanaugh A, Gladman DD, Mease PJ, Helliwell P, Boehncke WH, et al. Treatment recommendations for psoriatic arthritis. Ann Rheum Dis 2009;68:1387-94.

4. Gossec L, Smolen JS, Ramiro S, de Wit M, Cutolo M, Dougados $\mathrm{M}$, et al. European League Against Rheumatism (EULAR) recommendations for the management of psoriatic arthritis with pharmacological therapies: 2015 update. Ann Rheum Dis 2016;75:499-510.

5. Coates LC, Kavanaugh A, Mease PJ, Soriano ER, Laura Acosta-Felquer M, Armstrong AW, et al. Group for Research and Assessment of Psoriasis and Psoriatic Arthritis 2015 Treatment Recommendations for Psoriatic Arthritis. Arthritis Rheumatol 2016;68:1060-71.

6. Wendling D, Lukas C, Paccou J, Claudepierre $\mathrm{P}$, Carton L, Combe B, et al. Recommendations of the French Society for Rheumatology (SFR) on the everyday management of patients with spondyloarthritis. Joint Bone Spine 2014;81:6-14.

7. Marchesoni A, Olivieri I, Salvarani C, Pipitone N, D'Angelo S, Mathieu A, et al. Recommendations for the use of biologics and other novel drugs in the treatment of psoriatic arthritis: 2017 update from the Italian Society of Rheumatology. Clin Exp Rheumatol 2017;35:991-1010.

8. van der Heijde D, Aletaha D, Carmona L, Edwards CJ, Kvien TK, Kouloumas M, et al. 2014 Update of the EULAR standardised operating procedures for EULAR-endorsed recommendations. Ann Rheum Dis 2015;74:8-13.

9. Barnas JL, Ritchlin CT. Etiology and Pathogenesis of Psoriatic Arthritis. Rheum Dis Clin North Am 2015;41:643-63.

10. Kane D, Stafford L, Bresnihan B, FitzGerald O. A prospective, clinical and radiological study of early psoriatic arthritis: an early synovitis clinic experience. Rheumatology (Oxford) 2003;42:1460-8.

11. Ward MM, Leigh JP, Fries JF. Progression of functional disability in patients with rheumatoid arthritis. Associations with rheumatology subspecialty care. Arch Intern Med 1993;153:2229-37.

12. Solomon DH, Bates DW, Panush RS, Katz JN. Costs, outcomes, and patient satisfaction by provider type for patients with rheumatic and musculoskeletal conditions: a critical review of the literature and proposed methodologic standards. Ann Intern Med 1997; 127:52-60.

13. Zangi HA, Ndosi M, Adams J, Andersen L, Bode C, Boström C, et al. EULAR recommendations for patient education for people with inflammatory arthritis. Ann Rheum Dis 2015;74:954-62.

14. Lindström Egholm C, Krogh NS, Pincus T, Dreyer L, Ellingsen T, Glintborg B, et al. Discordance of Global Assessments by Patient and Physician Is Higher in Female than in Male Patients Regardless of the Physician's Sex: Data on Patients with Rheumatoid Arthritis, Axial Spondyloarthritis, and Psoriatic Arthritis from the DANBIO Registry. J Rheumatol 2015;42:1781-5.

15. Dandorfer SW, Rech J, Manger B, Schett G, Englbrecht M. Differences in the patient's and the physician's perspective of disease in psoriatic arthritis. Semin Arthritis Rheum 2012;42:32-41.

16. Hifinger M, Hiligsmann M, Ramiro S, Severens JL, Fautrel B, Watson V, et al. Patients' preferences and economic considerations play an important role in treatment decisions: a discrete choice experiment among rheumatologists. Rheumatology (Oxford) 2017;56:68-76.

17. Wallenius M, Skomsvoll JF, Koldingsnes W, Rødevand E, Mikkelsen K, Kaufmann C, et al. Work disability and health-related quality of life in males and females with psoriatic arthritis. Ann Rheum Dis 2009;68:685-9.

18. Singh JA, Strand V. Spondyloarthritis is associated with poor function and physical health-related quality of life. J Rheumatol 2009;36:1012-20.

19. Zhu TY, Tam LS, Leung YY, Kwok LW, Wong $\mathrm{KC}, \mathrm{Yu} \mathrm{T}$, et al. Socioeconomic burden of psoriatic arthritis in Hong Kong: direct and indirect costs and the influence of disease pattern. J Rheumatol 2010;37:1214-20. 
20. Bond SJ, Farewell VT, Schentag CT, Gladman DD. Predictors for radiological damage in psoriatic arthritis: results from a single centre. Ann Rheum Dis 2007;66:370-6.

21. Lindquist UR, Alenius GM, Husmark T, Theander E, Holmström G, Larsson PT. The Swedish early psoriatic arthritis register-- 2-year followup: a comparison with early rheumatoid arthritis. J Rheumatol 2008;35:668-73.

22. Theander E, Husmark T, Alenius GM, Larsson PT, Teleman A, Geijer M, et al. Early psoriatic arthritis: short symptom duration, male gender and preserved physical functioning at presentation predict favourable outcome at 5-year follow-up. Results from the Swedish Early Psoriatic Arthritis Register (SwePsA). Ann Rheum Dis 2014;73:407-13.

23. McHugh NJ, Balachrishnan C, Jones SM. Progression of peripheral joint disease in psoriatic arthritis: a 5-yr prospective study. Rheumatology (Oxford) 2003;42:778-83.

24. Coates LC, Cook R, Lee KA, Chandran V, Gladman DD. Frequency, predictors, and prognosis of sustained minimal disease activity in an observational psoriatic arthritis cohort. Arthritis Care Res (Hoboken) 2010;62:970-6.

25. Aletaha D, Alasti F, Smolen JS. Disease activity states of the DAPSA, a psoriatic arthritis specific instrument, are valid against functional status and structural progression. Ann Rheum Dis 2017;76:418-21.

26. Husni ME. Comorbidities in Psoriatic Arthritis. Rheum Dis Clin North Am 2015;41:677-98.

27. Ogdie A, Schwartzman S, Husni ME. Recognizing and managing comorbidities in psoriatic arthritis. Curr Opin Rheumatol 2015;27:118-26.

28. Nas K, Karkucak M, Durmus B, Karatay S, Capkın E, Kaya A, et al. Comorbidities in patients with psoriatic arthritis: a comparison with rheumatoid arthritis and psoriasis. Int $\mathrm{J}$ Rheum Dis 2015;18:873-9.

29. Polachek A, Li S, Polachek IS, Chandran V, Gladman D. Psoriatic arthritis disease activity during pregnancy and the first-year postpartum. Semin Arthritis Rheum 2017;46:740-5.

30. Kaine JL, Kivitz AJ, Birbara C, Luo AY. Immune responses following administration of influenza and pneumococcal vaccines to patients with rheumatoid arthritis receiving adalimumab. $\mathrm{J}$ Rheumatol 2007;34:272-9.

31. Gelinck LB, van der Bijl AE, Visser LG, Huizinga TW, van Hogezand RA, Rijkers GT, et al. Synergistic immunosuppressive effect of anti-TNF combined with methotrexate on antibody responses to the 23 valent pneumococcal polysaccharide vaccine. Vaccine 2008;26:3528-33.

32. Polachek A, Korobko U, Mader-Balakirski N, Arad U, Levartovsky D, Kaufman I, et al. Immunogenicity and safety of vaccination against seasonal 2012 influenza virus among patients with psoriatic arthritis and psoriasis. Clin Exp Rheumatol 2015;33:181-6.

33. Kapetanovic MC, Saxne T, Sjöholm A, Truedsson L, Jönsson G, Geborek P. Influence of methotrexate, TNF blockers and prednisolone on antibody responses to pneumococcal polysaccharide vaccine in patients with rheumatoid arthritis. Rheumatology (Oxford) 2006;45:106-11.

34. Caso F, Ramonda R, Del Puente A, Darda MA, Cantarini L, Peluso R, et al. Influenza vaccine with adjuvant on disease activity in psoriatic arthritis patients under anti-TNF- $\alpha$ therapy. Clin Exp Rheumatol 2016;34:507-12.

35. Friedman MA, Winthrop KL. Vaccines and diseasemodifying antirheumatic drugs: practical implications for the rheumatologist. Rheum Dis Clin North Am 2017;43:1-13.

36. Harel-Meir M, Sherer Y, Shoenfeld Y. Tobacco smoking and autoimmune rheumatic diseases. Nat Clin Pract Rheumatol 2007;3:707-15.

37. Tillett $\mathrm{W}$, Jadon $\mathrm{D}$, Shaddick G, Cavill C, Korendowych E, de Vries CS, et al. Smoking and delay to diagnosis are associated with poorer functional outcome in psoriatic arthritis. Ann Rheum Dis 2013;72:1358-61.

38. Bremander A, Jacobsson LT, Bergman S, Haglund E, Lofvendahl S, Petersson IF. Smoking is associated with a worse self-reported health status in patients with psoriatic arthritis: data from a Swedish population-based cohort. Clin Rheumatol 2015;34:579-83.

39. Coppack SW. Pro-inflammatory cytokines and adipose tissue. Proc Nutr Soc 2001;60:349-56.

40. Di Minno MN, Peluso R, Iervolino S, Russolillo A, Lupoli R, Scarpa R. Weight loss and achievement of minimal disease activity in patients with psoriatic arthritis starting treatment with tumour necrosis factor $\alpha$ blockers. Ann Rheum Dis 2014;73:1157-62.

41. Kjeken I, Bø I, Rønningen A, Spada C, Mowinckel $\mathrm{P}$, Hagen $\mathrm{KB}$, et al. A three-week multidisciplinary in-patient rehabilitation programme had positive long-term effects in patients with ankylosing spondylitis: randomized controlled trial. J Rehabil Med 2013;45:260-7.

42. McCuish WJ, Bearne LM. Do inpatient multidisciplinary rehabilitation programmes improve health status in people with long-term musculoskeletal conditions? A service evaluation. Musculoskeletal Care 2014;12:244-50.

43. van der Heijde D, Ramiro S, Landewé R, Baraliakos X, Van den Bosch F, Sepriano A, et al. 2016 update of the ASAS-EULAR management recommendations for axial spondyloarthritis. Ann Rheum Dis 2017;76:978-91.

44. Ozgocmen S, Akgul O, Altay Z, Altindag O, Baysal O, Calis M, et al. Expert opinion and key recommendations for the physical therapy and 
rehabilitation of patients with ankylosing spondylitis. Int J Rheum Dis 2012;15:229-38.

45. Roger-Silva D, Natour J, Moreira E, Jennings F. A resistance exercise program improves functional capacity of patients with psoriatic arthritis: a randomized controlled trial. Clin Rheumatol 2018;37:389-95.

46. Kirkham B, de Vlam K, Li W, Boggs R, Mallbris $\mathrm{L}$, Nab HW, et al. Early treatment of psoriatic arthritis is associated with improved patient-reported outcomes: findings from the etanercept PRESTA trial. Clin Exp Rheumatol 2015;33:11-9.

47. Kerschbaumer A, Baker D, Smolen JS, Aletaha D. The effects of structural damage on functional disability in psoriatic arthritis. Ann Rheum Dis 2017;76:2038-45.

48. Haroon M, Gallagher P, FitzGerald O. Diagnostic delay of more than 6 months contributes to poor radiographic and functional outcome in psoriatic arthritis. Ann Rheum Dis 2015;74:1045-50.

49. D'Angelo S, Palazzi C, Gilio M, Leccese P, Padula A, Olivieri I. Improvements in diagnostic tools for early detection of psoriatic arthritis. Expert Rev Clin Immunol 2016;12:1209-15.

50. Smolen JS, Breedveld FC, Burmester GR, Bykerk V, Dougados M, Emery P, et al. Treating rheumatoid arthritis to target: 2014 update of the recommendations of an international task force. Ann Rheum Dis 2016;75:3-15.

51. Coates LC, Moverley AR, McParland L, Brown S, Navarro-Coy N, O'Dwyer JL, et al. Effect of tight control of inflammation in early psoriatic arthritis (TICOPA): a UK multicentre, open-label, randomised controlled trial. Lancet 2015;386:2489-98.

52. Smolen JS, Schols M, Braun J, Dougados M, FitzGerald O, Gladman DD, et al. Treating axial spondyloarthritis and peripheral spondyloarthritis, especially psoriatic arthritis, to target: 2017 update of recommendations by an international task force. Ann Rheum Dis 2018;77:3-17.

53. Stoffer MA, Schoels MM, Smolen JS, Aletaha D, Breedveld FC, Burmester G, et al. Evidence for treating rheumatoid arthritis to target: results of a systematic literature search update. Ann Rheum Dis 2016;75:16-22.

54. Smolen JS, Braun J, Dougados M, Emery P, Fitzgerald $\mathrm{O}$, Helliwell $\mathrm{P}$, et al. Treating spondyloarthritis, including ankylosing spondylitis and psoriatic arthritis, to target: recommendations of an international task force. Ann Rheum Dis 2014;73:6-16.

55. Van den Bosch F, Kavanaugh A, Kron M, Kupper $\mathrm{H}$, Mease PJ. Clinical remission in patients with active psoriatic arthritis treated with adalimumab and correlations in joint and skin manifestations. $J$ Rheumatol 2015;42:952-9.

56. Schoels MM, Aletaha D, Alasti F, Smolen JS. Disease activity in psoriatic arthritis (PsA): defining remission and treatment success using the DAPSA score. Ann Rheum Dis 2016;75:811-8.

57. Cantini F, Niccoli L, Cassarà E, Kaloudi O, Nannini C. Sustained maintenance of clinical remission after adalimumab dose reduction in patients with early psoriatic arthritis: a long-term follow-up study. Biologics 2012;6:201-6.

58. Cantini F, Niccoli L, Nannini C, Cassara E, Pasquetti $\mathrm{P}$, Olivieri I, et al. Frequency and duration of clinical remission in patients with peripheral psoriatic arthritis requiring second-line drugs. Rheumatology (Oxford) 2008;47:872-6.

59. Salaffi F, Ciapetti A, Carotti M, Gasparini S, Gutierrez M. Disease activity in psoriatic arthritis: comparison of the discriminative capacity and construct validity of six composite indices in a real world. Biomed Res Int 2014;2014:528105.

60. Coates LC, FitzGerald O, Merola JF, Smolen J, van Mens LJJ, Bertheussen H, et al. Group for Research and Assessment of Psoriasis and Psoriatic Arthritis/ Outcome Measures in Rheumatology ConsensusBased Recommendations and Research Agenda for Use of Composite Measures and Treatment Targets in Psoriatic Arthritis. Arthritis Rheumatol 2018;70:345-55.

61. Mumtaz A, Gallagher P, Kirby B, Waxman R, Coates LC, Veale JD, et al. Development of a preliminary composite disease activity index in psoriatic arthritis. Ann Rheum Dis 2011;70:272-7.

62. Ogdie A, de Wit M, Callis Duffin K, Campbell W, Chau J, Coates LC, et al. Defining Outcome Measures for Psoriatic Arthritis: A Report from the GRAPPA-OMERACT Working Group. J Rheumatol 2017;44:697-700.

63. Coates LC, Helliwell PS. Defining low disease activity states in psoriatic arthritis using novel composite disease instruments. J Rheumatol 2016;4:371-5.

64. Helliwell PS, FitzGerald O, Fransen J, Gladman DD, Kreuger GG, Callis-Duffin K, et al. The development of candidate composite disease activity and responder indices for psoriatic arthritis (GRACE project). Ann Rheum Dis 2013;72:986-91.

65. Schoels M, Aletaha D, Funovits J, Kavanaugh A, Baker D, Smolen JS. Application of the DAREA/ DAPSA score for assessment of disease activity in psoriatic arthritis. Ann Rheum Dis 2010;69:1441-7.

66. Coates LC, Fransen J, Helliwell PS. Defining minimal disease activity in psoriatic arthritis: a proposed objective target for treatment. Ann Rheum Dis 2010;69:48-53.

67. Coates LC, Helliwell PS. Validation of minimal disease activity criteria for psoriatic arthritis using interventional trial data. Arthritis Care Res (Hoboken) 2010;62:965-9.

68. Coates LC, Navarro-Coy N, Brown SR, Brown S, McParland L, Collier H, et al. The TICOPA protocol (TIght COntrol of Psoriatic Arthritis): a randomised controlled trial to compare intensive management versus standard care in early psoriatic arthritis. BMC 
Musculoskelet Disord 2013;14:101.

69. Orbai AM, de Wit M, Mease PJ, Callis Duffin K, Elmamoun M, Tillett $\mathrm{W}$, et al. Updating the psoriatic arthritis (PsA) core domain set: A report from the PsA workshop at OMERACT 2016. J Rheumatol 2017;44:1522-8.

70. Ash Z, Gaujoux-Viala C, Gossec L, Hensor EM, FitzGerald O, Winthrop $\mathrm{K}$, et al. A systematic literature review of drug therapies for the treatment of psoriatic arthritis: current evidence and metaanalysis informing the EULAR recommendations for the management of psoriatic arthritis. Ann Rheum Dis 2012;71:319-26.

71. Sarzi-Puttini P, Santandrea S, Boccassini L, Panni $\mathrm{B}$, Caruso I. The role of NSAIDs in psoriatic arthritis: evidence from a controlled study with nimesulide. Clin Exp Rheumatol. 2001;19(1 Suppl 22):S17-20.

72. Sakkas LI, Alexiou I, Simopoulou T, Vlychou M. Enthesitis in psoriatic arthritis. Semin Arthritis Rheum 2013;43:325-34.

73. Borer JS, Simon LS. Cardiovascular and gastrointestinal effects of COX-2 inhibitors and NSAIDs: achieving a balance. Arthritis Res Ther 2005;7 Suppl 4:S14-22.

74. Eder L, Chandran V, Ueng J, Bhella S, Lee KA, Rahman P, et al. Predictors of response to intra-articular steroid injection in psoriatic arthritis. Rheumatology (Oxford) 2010;49:1367-73.

75. Braun J, Bollow M, Seyrekbasan F, Haberle HJ, Eggens U, Mertz A, et al. Computed tomography guided corticosteroid injection of the sacroiliac joint in patients with spondyloarthropathy with sacroiliitis: clinical outcome and followup by dynamic magnetic resonance imaging. J Rheumatol 1996;23:659-64.

76. Günaydin I, Pereira PL, Daikeler T, Mohren M, Trübenbach J, Schick F, et al. Magnetic resonance imaging guided corticosteroid injection of the sacroiliac joints in patients with therapy resistant spondyloarthropathy: a pilot study. J Rheumatol 2000;27:424-8

77. Jee H, Lee JH, Park KD, Ahn J, Park Y. Ultrasoundguided versus fluoroscopy-guided sacroiliac joint intra-articular injections in the noninflammatory sacroiliac joint dysfunction: a prospective, randomized, single-blinded study. Arch Phys Med Rehabil 2014;95:330-7.

78. Ritchlin CT. Therapies for psoriatic enthesopathy. A systematic review. J Rheumatol 2006;33:1435-8.

79. Baker H, Ryan TJ. Generalized pustular psoriasis. A clinical and epidemiological study of 104 cases. Br J Dermatol 1968;80:771-93.

80. Grassi W, De Angelis R, Cervini C. Corticosteroid prescribing in rheumatoid arthritis and psoriatic arthritis. Clin Rheumatol 1998;17:223-6.

81. Coates LC, Helliwell PS. Psoriasis flare with corticosteroid use in psoriatic arthritis. Br J Dermatol
2016;174:219-21.

82. Hoes JN, Jacobs JW, Verstappen SM, Bijlsma JW, Van der Heijden GJ. Adverse events of low- to medium-dose oral glucocorticoids in inflammatory diseases: a meta-analysis. Ann Rheum Dis 2009;68:1833-8.

83. Zink A, Thiele K, Huscher D, Listing J, Sieper J, Krause $\mathrm{A}$, et al. Healthcare and burden of disease in psoriatic arthritis. A comparison with rheumatoid arthritis and ankylosing spondylitis. J Rheumatol 2006;33:86-90

84. Fendler C, Baraliakos X, Braun J. Glucocorticoid treatment in spondyloarthritis. Clin Exp Rheumatol 2011;29(5 Suppl 68):S139-42.

85. Roussou E, Bouraoui A. Real-life experience of using conventional disease-modifying antirheumatic drugs (DMARDs) in psoriatic arthritis (PsA). Retrospective analysis of the efficacy of methotrexate, sulfasalazine, and leflunomide in PsA in comparison to spondyloarthritides other than PsA and literature review of the use of conventional DMARDs in PsA. Eur J Rheumatol 2017;4:1-10.

86. Simon P, Pfoehler C, Bergner R, Schreiber M, Pfreundschuh M, Assmann G. Swollen joint count in psoriatic arthritis is associated with progressive radiological damage in hands and feet. Clin Exp Rheumatol 2012;30:45-50.

87. Cresswell L, Chandran V, Farewell VT, Gladman DD. Inflammation in an individual joint predicts damage to that joint in psoriatic arthritis. Ann Rheum Dis 2011;70:305-8.

88. Brockbank JE, Stein M, Schentag CT, Gladman DD. Dactylitis in psoriatic arthritis: a marker for disease severity? Ann Rheum Dis 2005;64:188-90.

89. Mease PJ, Karki C, Palmer JB, Etzel CJ, Kavanaugh A, Ritchlin CT, et al. Clinical characteristics, disease activity, and patient-reported outcomes in psoriatic arthritis patients with dactylitis or enthesitis: results from the corrona psoriatic arthritis/spondyloarthritis registry. Arthritis Care Res (Hoboken) 2017;69:16921699.

90. Gladman DD, Thavaneswaran A, Chandran V, Cook RJ. Do patients with psoriatic arthritis who present early fare better than those presenting later in the disease? Ann Rheum Dis 2011;70:2152-4.

91. Kingsley GH, Kowalczyk A, Taylor H, Ibrahim F, Packham JC, McHugh NJ, et al. A randomized placebo-controlled trial of methotrexate in psoriatic arthritis. Rheumatology (Oxford) 2012;51:1368-77.

92. Lie $\mathrm{E}$, van der Heijde D, Uhlig T, Heiberg MS, Koldingsnes W, Rødevand E, et al. Effectiveness and retention rates of methotrexate in psoriatic arthritis in comparison with methotrexate-treated patients with rheumatoid arthritis. Ann Rheum Dis 2010;69:671-6.

93. Schmitt J, Rosumeck S, Thomaschewski G, Sporbeck B, Haufe E, Nast A. Efficacy and safety of systemic treatments for moderate-to-severe psoriasis: 
meta-analysis of randomized controlled trials. $\mathrm{Br} \mathrm{J}$ Dermatol 2014;170:274-303.

94. Eder L, Thavaneswaran A, Chandran V, Gladman DD. Tumour necrosis factor $\alpha$ blockers are more effective than methotrexate in the inhibition of radiographic joint damage progression among patients with psoriatic arthritis. Ann Rheum Dis 2014;73:1007-11.

95. Ramiro S, Smolen JS, Landewé R, van der Heijde D, Dougados M, Emery P, et al. Pharmacological treatment of psoriatic arthritis: a systematic literature review for the 2015 update of the EULAR recommendations for the management of psoriatic arthritis. Ann Rheum Dis 2016;75:490-8.

96. Ungprasert P, Thongprayoon C, Davis JM. Indirect comparisons of the efficacy of biological agents in patients with psoriatic arthritis with an inadequate response to traditional disease-modifying antirheumatic drugs or to non-steroidal anti-inflammatory drugs: A meta-analysis. Semin Arthritis Rheum 2016;45:428-38.

97. Kavanaugh A, Mease PJ, Reimold AM, Tahir H, Rech J, Hall S, et al. Secukinumab for LongTerm Treatment of Psoriatic Arthritis: A Two-Year Followup From a Phase III, Randomized, DoubleBlind Placebo-Controlled Study. Arthritis Care Res (Hoboken) 2017;69:347-55.

98. McInnes IB, Mease PJ, Ritchlin CT, Rahman P, Gottlieb AB, Kirkham B, et al. Secukinumab sustains improvement in signs and symptoms of psoriatic arthritis: 2 year results from the phase 3 FUTURE 2 study. Rheumatology (Oxford) 2017;56:1993-2003.

99. van der Heijde D, Gladman DD, Kishimoto M, Okada M, Rathmann SS, Moriarty SR, et al. Efficacy and safety of ixekizumab in patients with active psoriatic arthritis: 52-week results from a phase III study (SPIRIT-P1). J Rheumatol 2018;45:367-77.

100. Nash P, Kirkham B, Okada M, Rahman P, Combe B, Burmester GR, et al. Ixekizumab for the treatment of patients with active psoriatic arthritis and an inadequate response to tumour necrosis factor inhibitors: results from the 24-week randomised, double-blind, placebo-controlled period of the SPIRIT-P2 phase 3 trial. Lancet 2017;389:2317-27.

101. McInnes IB, Kavanaugh A, Gottlieb AB, Puig L, Rahman P, Ritchlin C, et al. Efficacy and safety of ustekinumab in patients with active psoriatic arthritis: 1 year results of the phase 3, multicentre, double-blind, placebo-controlled PSUMMIT 1 trial. Lancet 2013;382:780-9.

102. Kavanaugh A, Puig L, Gottlieb AB, Ritchlin C, You Y, Li S, et al. Efficacy and safety of ustekinumab in psoriatic arthritis patients with peripheral arthritis and physician-reported spondylitis: post-hoc analyses from two phase III, multicentre, double-blind, placebo-controlled studies (PSUMMIT-1/PSUMMIT-2). Ann Rheum Dis $2016 ; 75: 1984-8$.
103. Kavanaugh A, Puig L, Gottlieb AB, Ritchlin C, $\mathrm{Li}$ S, Wang Y, et al. Maintenance of clinical efficacy and radiographic benefit through two years of ustekinumab therapy in patients with active psoriatic arthritis: Results from a randomized, placebo-controlled phase III trial. Arthritis Care Res (Hoboken) 2015;67:1739-49.

104. Kavanaugh A, Mease PJ, Gomez-Reino JJ, Adebajo AO, Wollenhaupt J, Gladman DD, et al. Treatment of psoriatic arthritis in a phase 3 randomised, placebo-controlled trial with apremilast, an oral phosphodiesterase 4 inhibitor. Ann Rheum Dis 2014;73:1020-6.

105. Edwards CJ, Blanco FJ, Crowley J, Birbara CA, Jaworski J, Aelion J, et al. Apremilast, an oral phosphodiesterase 4 inhibitor, in patients with psoriatic arthritis and current skin involvement: a phase III, randomised, controlled trial (PALACE 3). Ann Rheum Dis 2016;75:1065-73.

106. Cutolo M, Myerson GE, Fleischmann RM, Lioté F, Díaz-González F, Van den Bosch F, et al. A Phase III, Randomized, Controlled Trial of Apremilast in Patients with Psoriatic Arthritis: Results of the PALACE 2 Trial. J Rheumatol 2016;43:1724-34.

107. Bartelds GM, Krieckaert CL, Nurmohamed MT, van Schouwenburg PA, Lems WF, Twisk JW, et al. Development of antidrug antibodies against adalimumab and association with disease activity and treatment failure during long-term follow-up. JAMA 2011;305:1460-8.

108. Pascual-Salcedo D, Plasencia C, Ramiro S, Nuno L, Bonilla G, Nagore D, et al. Influence of immunogenicity on the efficacy of long-term treatment with infliximab in rheumatoid arthritis. Rheumatology (Oxford) 2011;50:1445-52.

109. Jani M, Barton A, Warren RB, Griffiths CE, Chinoy $H$. The role of DMARDs in reducing the immunogenicity of TNF inhibitors in chronic inflammatory diseases. Rheumatology (Oxford) 2014;53:213-22.

110. Dubey S, Kerrigan N, Mills K, Scott DG. Bronchospasm associated with anti-TNF treatment. Clin Rheumatol 2009;28:989-92.

111. Bendtzen K. Is there a need for immunopharmacologic guidance of anti-tumor necrosis factor therapies? Arthritis Rheum 2011;63:867-70.

112. Maggi E, Vultaggio A, Matucci A. Acute infusion reactions induced by monoclonal antibody therapy. Expert Rev Clin Immunol 2011;7:55-63.

113. Smolen JS, Landewé R, Bijlsma J, Burmester G, Chatzidionysiou $\mathrm{K}$, Dougados $\mathrm{M}$, et al. EULAR recommendations for the management of rheumatoid arthritis with synthetic and biological diseasemodifying antirheumatic drugs: 2016 update. Ann Rheum Dis 2017;76:960-77.

114. Behrens F, Canete JD, Olivieri I, van Kuijk AW, McHugh N, Combe B. Tumour necrosis factor inhibitor monotherapy vs combination with MTX 
in the treatment of PsA: a systematic review of the literature. Rheumatology (Oxford) 2015;54:915-26.

115. Gottlieb AB, Langley RG, Strober BE, Papp KA, Klekotka P, Creamer K, et al. A randomized, doubleblind, placebo-controlled study to evaluate the addition of methotrexate to etanercept in patients with moderate to severe plaque psoriasis. $\mathrm{Br} \mathrm{J}$ Dermatol 2012;167:649-57.

116. Zachariae C, Mørk NJ, Reunala T, Lorentzen H, Falk $\mathrm{E}$, Karvonen SL, et al. The combination of etanercept and methotrexate increases the effectiveness of treatment in active psoriasis despite inadequate effect of methotrexate therapy. Acta Derm Venereol 2008;88:495-501.

117. van den Reek JM, van Lümig PP, Kievit W, Zweegers $J$, van de Kerkhof PC, Seyger MM, et al. Effectiveness of adalimumab dose escalation, combination therapy of adalimumab with methotrexate, or both in patients with psoriasis in daily practice. J Dermatolog Treat 2013;24:361-8.

118. Wee JS, Petrof G, Jackson K, Barker JN, Smith CH. Infliximab for the treatment of psoriasis in the U.K.: 9 years' experience of infusion reactions at a single centre. Br J Dermatol 2012;167:411-6.

119. Choy E. T cells in psoriatic arthritis. Curr Rheumatol Rep 2007;9:437-41.

120. Cai Y, Fleming C, Yan J. New insights of T cells in the pathogenesis of psoriasis. Cell Mol Immunol 2012;9:302-9.

121. van Kuijk AW, Reinders-Blankert $P$, Smeets $T J$, Dijkmans BA, Tak PP. Detailed analysis of the cell infiltrate and the expression of mediators of synovial inflammation and joint destruction in the synovium of patients with psoriatic arthritis: implications for treatment. Ann Rheum Dis 2006;65:1551-7.

122. Szentpetery A, Heffernan E, Gogarty M, Mellerick L, McCormack J, Haroon M, et al. Abatacept reduces synovial regulatory T-cell expression in patients with psoriatic arthritis. Arthritis Res Ther 2017;19:158.

123. Mease P, Genovese MC, Gladstein G, Kivitz AJ, Ritchlin C, Tak PP, et al. Abatacept in the treatment of patients with psoriatic arthritis: results of a six-month, multicenter, randomized, double-blind, placebo-controlled, phase II trial. Arthritis Rheum 2011;63:939-48.

124. Mease PJ, Gottlieb $\mathrm{AB}$, van der Heijde $\mathrm{D}$, FitzGerald O, Johnsen A, Nys M, et al. Efficacy and safety of abatacept, a T-cell modulator, in a randomised, double-blind, placebo-controlled, phase III study in psoriatic arthritis. Ann Rheum Dis 2017;76:1550-8.

125. Mease P, Hall S, FitzGerald $\mathrm{O}$, van der Heijde D, Merola JF, Avila-Zapata F, et al. Tofacitinib or Adalimumab versus Placebo for Psoriatic Arthritis. N Engl J Med 2017;377:1537-50.

126. Gladman D, Rigby W, Azevedo VF, Behrens F, Blanco R, Kaszuba A, et al. Tofacitinib for Psoriatic Arthritis in Patients with an Inadequate Response to
TNF Inhibitors. N Engl J Med 2017;377:1525-36.

127. Asahina A, Etoh T, Igarashi A, Imafuku S, Saeki H, Shibasaki Y, et al. Oral tofacitinib efficacy, safety and tolerability in Japanese patients with moderate to severe plaque psoriasis and psoriatic arthritis: A randomized, double-blind, phase 3 study. J Dermatol 2016;43:869-80.

128. Orbai AM, Weitz J, Siegel EL, Siebert S, Savage LJ, Aydin SZ, et al. Systematic review of treatment effectiveness and outcome measures for enthesitis in psoriatic arthritis. J Rheumatol 2014;41:2290-4.

129. Clegg DO, Reda DJ, Mejias E, Cannon GW, Weisman $\mathrm{MH}$, Taylor T, et al. Comparison of sulfasalazine and placebo in the treatment of psoriatic arthritis. A Department of Veterans Affairs Cooperative Study. Arthritis Rheum 1996;39:2013-20.

130. Sterry W, Ortonne JP, Kirkham B, Brocq O, Robertson D, Pedersen RD, et al. Comparison of two etanercept regimens for treatment of psoriasis and psoriatic arthritis: PRESTA randomised double blind multicentre trial. BMJ 2010;340:147.

131. Kavanaugh A, Mclnnes I, Mease P, Krueger GG, Gladman D, Gomez-Reino J, et al. Golimumab, a new human tumor necrosis factor alpha antibody, administered every four weeks as a subcutaneous injection in psoriatic arthritis: Twenty-four-week efficacy and safety results of a randomized, placebocontrolled study. Arthritis Rheum 2009;60:976-86.

132. Mease PJ, Fleischmann R, Deodhar AA, Wollenhaupt $J$, Khraishi M, Kielar D, et al. Effect of certolizumab pegol on signs and symptoms in patients with psoriatic arthritis: 24-week results of a Phase 3 double-blind randomised placebo-controlled study (RAPID-PsA). Ann Rheum Dis 2014;73:48-55.

133. Kavanaugh A, Mease PJ, Gomez-Reino JJ, Adebajo AO, Wollenhaupt J, Gladman DD, et al. Longterm (52-week) results of a phase III randomized, controlled trial of apremilast in patients with psoriatic arthritis. J Rheumatol 2015;42:479-88.

134. Rose S, Toloza S, Bautista-Molano W, Helliwell PS. Comprehensive treatment of dactylitis in psoriatic arthritis. J Rheumatol 2014;41:2295-300.

135. Corbett M, Soares M, Jhuti G, Rice S, Spackman E, Sideris $\mathrm{E}$, et al. Tumour necrosis factor- $\alpha$ inhibitors for ankylosing spondylitis and non-radiographic axial spondyloarthritis: a systematic review and economic evaluation. Health Technol Assess 2016;20:1-334.

136. Callhoff J, Sieper J, Weiss A, Zink A, Listing J. Efficacy of TNFalpha blockers in patients with ankylosing spondylitis and non-radiographic axial spondyloarthritis: a meta-analysis. Ann Rheum Dis 2015;74:1241-8.

137. Baeten D, Sieper J, Braun J, Baraliakos X, Dougados M, Emery P, et al. Secukinumab, an Interleukin-17A Inhibitor, in Ankylosing Spondylitis. N Engl J Med 2015;373:2534-48.

138. Braun J, Baraliakos X, Deodhar A, Baeten D, Sieper J, Emery P, et al. Effect of secukinumab on 
clinical and radiographic outcomes in ankylosing spondylitis: 2-year results from the randomised phase III MEASURE 1 study. Ann Rheum Dis 2017;76:1070-7.

139. Pavelka K, Kivitz A, Dokoupilova E, Blanco R, Maradiaga M, Tahir $\mathrm{H}$, et al. Efficacy, safety, and tolerability of secukinumab in patients with active ankylosing spondylitis: a randomized, double-blind phase 3 study, MEASURE 3. Arthritis Res Ther 2017;19:285.

140. Baraliakos X, Kivitz AJ, Deodhar AA, Braun J, Wei JC, Delicha EM, et al. Long-term effects of interleukin-17A inhibition with secukinumab in active ankylosing spondylitis: 3-year efficacy and safety results from an extension of the Phase 3 MEASURE 1 trial. Clin Exp Rheumatol 2018;36:50-5.

141. Kavanaugh A, Ritchlin C, Rahman P, Puig L, Gottlieb $\mathrm{AB}, \mathrm{Li} \mathrm{S}$, et al. Ustekinumab, an anti-IL-12/23 p40 monoclonal antibody, inhibits radiographic progression in patients with active psoriatic arthritis: results of an integrated analysis of radiographic data from the phase 3 , multicentre, randomised, double-blind, placebo-controlled PSUMMIT-1 and PSUMMIT-2 trials. Ann Rheum Dis 2014;73:1000-6.

142. Chen J, Lin S, Liu C. Sulfasalazine for ankylosing spondylitis. Cochrane Database Syst Rev 2014:CD004800.

143. Nash P. Therapies for axial disease in psoriatic arthritis. A systematic review. J Rheumatol 2006;33:1431-4.

144. Simone D, Nowik M, Gremese E, Ferraccioli GF. Disease-modifying Antirheumatic Drugs (DMARD) and Combination Therapy of Conventional DMARD in Patients with Spondyloarthritis and Psoriatic Arthritis with Axial Involvement. J Rheumatol Suppl 2015;93:65-9.

145. American Academy of Dermatology Work Group, Menter A, Korman NJ, Elmets CA, Feldman SR, Gelfand JM, Gordon KB, et al. Guidelines of care for the management of psoriasis and psoriatic arthritis: section 6. Guidelines of care for the treatment of psoriasis and psoriatic arthritis: case-based presentations and evidence-based conclusions. J Am Acad Dermatol 2011;65:137-74.

146. Li WQ, Han JL, Chan AT, Qureshi AA. Psoriasis, psoriatic arthritis and increased risk of incident Crohn's disease in US women. Ann Rheum Dis 2013;72:1200-5.

147. Sandborn WJ, Feagan BG, Stoinov S, Honiball PJ, Rutgeerts P, Mason D, et al. Certolizumab pegol for the treatment of Crohn's disease. N Engl J Med 2007;357:228-38.

148. Adedokun OJ, Xu Z, Marano CW, Strauss R, Zhang $\mathrm{H}$, Johanns $\mathrm{J}$, et al. Pharmacokinetics and Exposure-response Relationship of Golimumab in Patients with Moderately-to-Severely Active Ulcerative Colitis: Results from Phase 2/3 PURSUIT Induction and Maintenance Studies.
J Crohns Colitis 2017;11:35-46.

149. Sandborn WJ, Hanauer SB, Rutgeerts P, Fedorak RN, Lukas M, MacIntosh DG, et al. Adalimumab for maintenance treatment of Crohn's disease: results of the CLASSIC II trial. Gut 2007;56:1232-9.

150. Vickers AD, Ainsworth C, Mody R, Bergman A, Ling CS, Medjedovic J, et al. Systematic Review with Network Meta-Analysis: Comparative Efficacy of Biologics in the Treatment of Moderately to Severely Active Ulcerative Colitis. PLoS One 2016;11:e0165435.

151. Zhou Z, Dai C, Liu WX. Anti-TNF-A Therapy about Infliximab and Adalimamab for the Effectiveness in Ulcerative Colitis Compared with Conventional Therapy: A Meta-Analysis. Hepatogastroenterology 2015;62:829-37.

152. Kawalec P, Mocko P, Malinowska-Lipien I, Brzostek $T$. Efficacy and safety of ustekinumab in the induction therapy of TNF-alpha-refractory Crohn's disease patients: a systematic review and meta-analysis. J Comp Eff Res 2017;6:601-12.

153. HueberW, Sands BE, LewitzkyS, Vandemeulebroecke M, Reinisch W, Higgins PD, et al. Secukinumab, a human anti-IL-17A monoclonal antibody, for moderate to severe Crohn's disease: unexpected results of a randomised, double-blind placebocontrolled trial. Gut. 2012;61:1693-700.

154. Glintborg B, Ostergaard M, Krogh NS, Andersen MD, Tarp U, Loft AG, et al. Clinical response, drug survival, and predictors thereof among 548 patients with psoriatic arthritis who switched tumor necrosis factor $\alpha$ inhibitor therapy: results from the Danish Nationwide DANBIO Registry. Arthritis Rheum 2013;65:1213-23.

155. Fagerli KM, Lie E, van der Heijde D, Heiberg MS, Kalstad S, Rodevand E, et al. Switching between TNF inhibitors in psoriatic arthritis: data from the NOR-DMARD study. Ann Rheum Dis 2013;72:1840-4.

156. Kristensen LE, Lie E, Jacobsson LT, Christensen $\mathrm{R}$, Mease PJ, Bliddal $\mathrm{H}$, et al. Effectiveness and Feasibility Associated with Switching to a Second or Third TNF Inhibitor in Patients with Psoriatic Arthritis: A Cwohort Study from Southern Sweden. J Rheumatol 2016;43:81-7.

157. McInnes IB, Mease PJ, Kirkham B, Kavanaugh A, Ritchlin CT, Rahman P, et al. Secukinumab, a human anti-interleukin-17A monoclonal antibody, in patients with psoriatic arthritis (FUTURE 2): a randomised, double-blind, placebo-controlled, phase 3 trial. Lancet 2015;386:1137-46.

158. Jorgensen KK, Olsen IC, Goll GL, Lorentzen M, Bolstad N, Haavardsholm EA, et al. Switching from originator infliximab to biosimilar CT-P13 compared with maintained treatment with originator infliximab (NOR-SWITCH): a 52-week, randomised, doubleblind, non-inferiority trial. Lancet 2017;389:2304-16. 